\title{
EL BREXIT: TODO UN RETO PARA EL DERECHO ROMANO
}

\author{
Alfonso Murillo Villar \\ Universidad de Burgos, Espanha
}

\begin{abstract}
"Quiero destacar lo importante que su tarea investigadora es para la Unión Europea, y ello, en cuanto el derecho romano constituye una de las bases culturales indispensables de Europa y uno de los elementos esenciales de nuestra identidad. La comunidad de derecho que es la Unión Europea se fundamenta en sus raíces, que aún hoy sostienen nuestra cultura jurídica común. ¡Gracias por su labor y enhorabuena!”
\end{abstract}

Antonio Tajani ${ }^{1}$

Presidente del Parlamento Europeo

12 de abril de 2019

RESUMEN: Con la salida del Reino Unido de la Unión Europea también lo hace el sistema jurídico anglosajón o Common Law. Esta circunstancia facilita la futura armonización legal entre todos los sistemas jurídicos del denominado Civil Law o derecho continental, sistema jurídico por el que se rigen los países, a excepción de Irlanda, que permanecen en la Unión. A partir de ahora, será más fácil crear una ciencia jurídica europea común de base romanista, pues el Derecho romano se convierte en su único y fundamental elemento aglutinador: el ordenamiento jurídico romano es la base común de todos los ordenamientos jurídicos de la Europa continental. Es el momento de hacer valer la influencia romanística en la configuración del futuro ordenamiento jurídico común europeo.

PALABRAS CLAVE: Brexit. Common Law. Civil Law. Derecho Romano. Derecho europeo.

\section{Brexit: a great challenge for Roman Law}

ABSTRACT: With the exit of the United Kingdom from the European Union, the Common Law legal system is also removed. This circumstance facilitates future legal harmonization between the so-called legal system of Civil Law or continental law, the legal system that regulates the countries, with the exception of Ireland, that remain in the Union. It will henceforth be easier to create a common European legal science based on Roman law, as Roman law is converted into its single and fundamental unifying element: the Roman legal order is the common foundation of all the legal orders of Continental Europe. It is time to assert the influence of Roman law in the future configuration of the common European legal order.

KEYWORDS: Brexit. Common Law. Civil Law. Roman Law. European Law.

\section{Brexit: um grande desafio para o Direito Romano}

RESUMO: Com a saída do Reino Unido da União Europeia, também o faz o sistema jurídico anglossaxão ou Common Law. Esta circunstância facilita a futura harmonização legal entre todos os sistemas jurídicos do denominado Civil Law ou direito continental, sistema jurídico pelo qual

1 Palabras del mensaje remitido por el Presidente del Parlamento Europeo, D. ANTONIO TAJANI, con motivo de la conmemoración del $\mathrm{XXV}^{\mathrm{o}}$ aniversario de la Asociación Iberoamericana de Derecho Romano (AIDROM), que tuvo lugar durante la celebración del XXI Congreso Internacional y XXIV Congreso Iberoamericano de Derecho Romano, entre los días 10 a 12 de abril de 2019 en el Edificio Histórico de la Universidad de Oviedo, y cuyo tema de debate fue: "Fundamentos romanísticos del derecho de la Unión Europea y de los países iberoamericanos". 
se regem os países, à exceção da Irlanda, que permanecem na União. A partir de agora, será mais fácil criar uma ciência jurídica europeia comum de base romanista, pois o Direito Romano se converte em seu único e fundamental elemento aglutinador: o ordenamento jurídico romano é a base comum de todos os ordenamentos jurídicos da Europa continental. É o momento de fazer valer a influência romanística na configuração do futuro ordenamento jurídico comum europeu. PALAVRAS-CHAVE: Brexit. Common Law. Civil Law. Direito Romano. Direito europeu.

\section{INTRODUCCIÓN}

El jueves 23 de junio de 2016 tuvo lugar un referéndum sobre la permanencia del Reino Unido (RU) en la Unión Europea (UE), que arrojó un resultado favorable a su salida con casi un $52 \%$ de los votos. A partir de ese momento se acuño el acrónimo Brexit, formado por las palabras inglesas Britain y exit, que significa salida del RU de la UE. El resultado del referéndum no era vinculante, pues para iniciar el proceso de salida de la UE, el Parlamento del RU tenía que derogar una serie de leyes, hasta que finalmente el 29 de marzo de 2017, tras conseguir dicha aprobación, el RU comunicó al presidente del Consejo Europeo su intención de abandonar la UE, tal y como establece el artículo 50 del Tratado de la Unión. Con esta comunicación dio inicio el proceso de salida, que según establece el Tratado, tiene una duración inicial de dos años. Pero ocho días antes de que expirase el plazo para que el RU abandonase la UE, el 21 de marzo de 2019, y ante la ausencia de acuerdo, la UE y el RU acordaron prorrogar la salida hasta el viernes 12 de abril. Y de nuevo, la víspera, el 11 de abril, se volvió a posponer la salida hasta el 31 de octubre del mismo año 2019.

Con el Brexit se ha abierto una crisis de consecuencias imprevisibles ${ }^{2}$. Sin duda, habrá consecuencias económicas, políticas, sociales e ideológicas, pero sobre todo, nos interesan las consecuencias jurídicas, y su repercusión en un pilar fundamental de la UE, que es su unificación jurídica. Es cierto que corren tiempos difíciles para Europa; tiempos difíciles para el derecho europeo; sin embargo, a los países que permanecen en la UE les resta un fundamental e inverosímil elemento aglutinador: el Derecho romano, base común de todos los ordenamientos jurídicos de la Europa continental. Al igual que el RU, también su ordenamiento jurídico, el conocido Common Law, ha sido un elemento incómodo, y hasta distorsionador, de la ineludible pretensión de unificación jurídica. Desaparecido el "problema", dicho con el mayor de los respetos, se nos brinda una gran oportunidad a los estudiosos del Derecho romano, para hacer valer nuestra influencia en la configuración del futuro ordenamiento común.

\section{El Common LaW abandona la Unión Europea}

Si partimos de que el Derecho romano está en el ADN del derecho europeo continental, todo lo que seguidamente digamos se comprenderá fácilmente ${ }^{3}$. Con más argumentos que nunca, desde la salida del RU de la UE, el Derecho romano se va a convertir en el referente único común de todos los ordenamientos de la Europa continental, para lograr su armonización o unificación ${ }^{4}$.

2 Sin duda, los recientes acontecimientos tienen su explicación en el desarrollo de la historia, vid. HEUSER B., Brexit in History: Sovereignty or a European Union?, London, Reino Unido, ed. C. Hurst \& Co. Ltd., 2019.

3 Vid. MURILlO VILLAR, A., ¿Para qué sirve el Derecho romano? Razones que justifican su docencia e investigación en el siglo XXI, Santiago de Compostela, Andavira, 2018.

4 De "interconexión de los distintos sistemas civiles nacionales" lo calificó Da SALLA SAASTAMOINEN, Directora para la Justicia Civil y Comercial. Directora General de Justicia y Consumidores de la Comisión Europea, en la Conferencia Inaugural del XXI Congreso Internacional y XXIV Iberoamericano de Derecho Romano, celebrada en la Universidad de Oviedo el día 10 de abril de 2019, para quien dicha expresión "significa tener en consideración la 
Es más, incluso ahora podríamos inclinarnos por hablar mejor de unificación que de armonización, pues es mucho más lo que nos une que lo que nos separa, jurídicamente hablando, a quienes permanecemos en la UE. Y decimos esto, porque la "dificultad" que implicaba la presencia del Commom Law, para intentar una unificación, ha desaparecido; tal obstáculo exigía, más bien, un proceso de armonización, que varió, según los casos, por las aspiraciones del conjunto. Si alguna ventaja otorga el Brexit, es la facilidad para lograr, a partir de ahora, una ciencia jurídica europea común de base romanista, pues su presencia siempre obstaculizó la ansiada unificación de los ordenamientos jurídicos continentales ${ }^{5}$.

Entendemos que no resulte fácil admitir esta afirmación, pero debemos aceptar la existencia de permanentes esfuerzos, por parte de la doctrina, para justificar las diferencias entre el Common Law y el Civil Law, las cuales, en ocasiones, son más profundas de lo que a veces se han querido presentar. No obstante, nadie podrá negar que siempre ha existido, por parte inglesa, una aversión innata a la codificación ${ }^{6}$. Aunque se pretendan desmentir dichas diferencias entre ambas tradiciones jurídicas, e intentar demostrar un progresivo acercamiento, que favoreciera una hipotética unificación jurídica europea, ha llegado el momento en que todo ese trabajo es innecesario $^{7}$. El RU ha abandonado la UE, y por consiguiente será superfluo conciliar ambos

tradición jurídica de los Estados miembros que, [...], a menudo tienen su origen en reglas, criterios y principios consagrados en el Derecho romano. El uso de términos jurídicos romanos en los sistemas legales de los Estados miembros facilita enfrentar este desafío. Trabajar con conceptos legales tradicionales resulta beneficioso, al permitirnos identificar un lenguaje común".

5 No obstante, Irlanda continúa en la UE como miembro de pleno derecho, y es un país que se rige por el Commom Law. Lógicamente, su pertenencia siempre determinará la legislación común, pero previsiblemente será menor que la determinación que ha tenido la presencia del RU. Por su influencia económica y social; por el porcentaje de población total de la UE, 0,9 \% en 2016; por el número de escaños en el Parlamento europeo, (11); por su contribución al presupuesto de la Unión en porcentaje de renta nacional bruta (RNB), $(0,86 \%)$, porque su moneda es el Euro, entre otras varias razones, hacen muy verosímil que en la futura unificación del derecho común europeo, el derecho anglosajón pierda influencia como contrapunto jurídico frente al derecho continental de base romanista.

6 ROBLES VELASCO, L. M., «El futuro código europeo de contratos, ¿una nueva recepción?», en RIDROM, $\mathrm{n}^{\circ} 5$, octubre 2010, p. 57-91.

7 Puede verse el trabajo de STÜRNER, M., «Tendiendo un puente entre el Common Law y el derecho continental. ¿Constituyen las diferentes metodologías de trabajo un obstáculo contra una mayor armonización del derecho privado europeo?», en Revista jurídica Universidad Autónoma de Madrid, n 15, 2007, p. 177-193, en el cual, el Autor tomando como punto de partida que estamos ante dos sistemas legales distintos, se esfuerza por demostrar que no son tan diferentes, e incluso afirma que las diferencias entre el Common Law y el Civil Law o derecho continental se han reducido. Quizás sea cierto, pero entre ambos sistemas existen diferencias sustanciales y si hasta ahora se trataban de evitar, a partir de ahora será absolutamente innecesario tal esfuerzo. Hay que recuperar la tradición histórica de nuestro sistema legal, en este momento con más legitimidad que nunca, detalle no extraño para STÜRNER pues reconoce in fine de su trabajo que "La convergencia de ambos sistemas ha estado progresando rápidamente. La importancia creciente del derecho comunitario ha conducido a una adopción de técnicas similares en la legislación y la interpretación de leyes en ambos lados del canal de la Mancha. Al pensar en mayor armonización, sin embargo, no debemos dejar de lado las tradiciones históricas de ambos sistemas en la medida en que ellas continúan influenciando el pensamiento legal en los diversos Estados miembros" (p. 193). Vid. HERZOG, T., Una breve historia del derecho europeo. Los últimos 2.500 años, Madrid, Alianza Editorial S.A., (trad. esp. COLL RODRÍGUEZ, M.A.), 2019, quien busca con esta obra poner en tela de juicio la presuposición de que el Common Law inglés y el derecho continental son completamente distintos. Para la Autora ambos sistemas forman parte de una sola tradición europea de la cual proceden y que enriquecía a los dos, siendo sustancialmente más similares de lo que a simple vista parece (p. 16). No obstante, indica (p. 331), que para algunos juristas las diferencias entre estos dos sistemas son verdaderamente insalvables. "Las epistemologías jurídicas importan más que las soluciones concretas que cada uno de estos sistemas adoptaron. En el nivel epistemológico, el derecho continental y el inglés son reconociblemente distintos, con diferentes enfoques sobre lo que es el derecho, quién lo creó y de qué modo podría cambiar. Mientras que los sistemas continentales se centran en la razón, el Common Law se basa en la experiencia; mientras que los sistemas continentales dan primacía a la legislación, el Common Law prefiere la jurisprudencia". Pero no soslaya TAMAR HERZOG (p. 332), que "estos juristas también señalan que hay importantes maneras en las cuales ambos sistemas han ido convergiendo gradualmente incluso en su marco conceptual, evolucionando hacia un terreno intermedio. Esta convergencia ha eliminado (o al menos minimizado) muchas de las diferencias entre los sistemas continental e inglés, no sólo al nivel de soluciones concretas (que con frecuencia son idénticas), sino también con respecto a cómo ven ellos la legislación y el derecho jurisprudencial, que ahora en ambos sistemas se consideran complementarios en vez de opuestos. En realidad, la mejor 
sistemas jurídicos de cara a una regulación futura común. Además, por más que se intente, son dos modelos jurídicos diferentes ${ }^{8}$, y ello quizás este influido porque la tradición romanística en el RU tuvo un efecto menor que en el continente. Es decir, la recepción del Derecho romano en Inglaterra tuvo como dificultad, entre otras, el marcado corporativismo de los juristas ingleses, porque el nuevo sistema ponía en peligro sus intereses profesionales ${ }^{9}$. Por lo tanto, con la nueva situación que ha provocado el Brexit, resulta inútil buscar puntos de conexión entre el Common Law y el Civil Law; ya no será necesario, porque el futuro derecho común europeo quedará circunscrito a los 27 países miembros actuales de la Unión, y a aquellos que se incorporen, que seguirán rigiéndose por ordenamientos de base romanística. Se trata de ordenamientos con una tradición jurídica y unas características comunes, que conducen a la individualización de lo que los comparatistas llaman un macro-sistema. Sistema que denominamos Civil Law o romanogermánico, y que une a los derechos francés, alemán, italiano, austriaco, español, portugués, etc. ${ }^{10}$, sin olvidar los iberoamericanos.

Se ha intentado, por muchos autores, ver cierta influencia del Derecho romano en el derecho anglosajón ${ }^{11}$, pero las dificultades son ciertamente enormes. Y, sobre todo, si lo vemos desde el punto de vista de la recepción del Derecho romano se puede afirmar que la influencia es reducida. Al menos, debe precisarse que la tradición romanística tuvo un efecto mucho menor en las Islas Británicas que en el continente europeo. Además, si la unificación del derecho europeo ha de basarse en el derecho privado, hay que decir que la influencia del Derecho privado romano en el derecho inglés no fue muy importante, y como mucho tuvo una naturaleza accidental $^{12}$. Quizás pueda achacarse, a que la enseñanza del Derecho romano tuvo mucha oposición; tal vez, porque se trataba de un ordenamiento fácilmente identificable con el Imperio, lo cual provocaba temor en la nobleza ante el posible fortalecimiento legislativo de la Corona ${ }^{13}$. En definitiva, lo cierto es que la influencia del Derecho romano no fue en Inglaterra como en la Europa continental, en donde triunfó el fenómeno codificador, en todos los ordenamientos jurídicos. Y aunque se afirme la impronta del Derecho romano sobre el Commom Law, hay que reconocer lo difícil y delicado que es comprender las razones de fondo de tal analogía ${ }^{14}$.

Sirva el irónico símil de KOSCHAKER ${ }^{15}$, para resumir nuestra opinión: "El Derecho romano viene a ser para los juristas ingleses, un venerable anciano de hermosas y luengas barbas,

prueba de semejante coexistencia pacífica es el propio derecho europeo". Por ello, como siempre se ha dicho, la única forma sensata de enfrentar el futuro es conociendo bien la historia, vid. VAN CAENEGEM, R.C., Pasado y futuro del derecho europeo, dos milenios de unidad y diversidad, Santiago de Chile, Chile, ed. Olejnik, 2019.

8 AJANI, G. et alii, Sistemas jurídicos comparados. Lecciones y materiales, (trad. español), Barcelona, Publicacions i Edicions, Universitat de Barcelona, 2010, p. 77 ss.; ACQUARONE, L. et alii, Sistemi giuridici nel mondo, $2^{\mathrm{a}}$ ed., Torino, Giappichelli Editore, 2016, p. 139 ss.; HAMZA, G., Origine e sviluppo degli ordinamenti giusprivatistici moderni in base alla tradizione del Diritto romano, Santiago de Compostela, Andavira, 2013, p. 28. GAMBARO, A. - SACCO, R., Sistemi giuridici comparati, $4^{\text {a }}$ ed., Utet Giuridica, Milano, 2018, p. 31 ss.

9 Vid., HERRERA BRAVO, R. - SALAZAR REVUELTA, Mª. - SALAZAR REVUELTA, A., «Ius Commune versus Derecho común europeo», en RGDR, nº. 10, 2008, especialmente a partir de p. 21 ss. FERNÁNDEZ DE BUJÁN, A., «Ciencia jurídica europea y derecho comunitario: Ius romanum. Ius commune. Cammon Law. Civil Law», en RGDR, $\mathrm{n}^{\circ}$ 10, 2008; el mismo trabajo revisado y con apéndice bibliográfico en GLOSSAE. European Journal of Legal History, $\mathrm{n}^{\mathrm{o}} 13,2016$, p. 276-306.

${ }^{10}$ AJANI et alii, Sistemas jurídicos comparados, cit., p. 245.

11 TORRENT, A., Fundamentos del derecho europeo. Ciencia del derecho: Derecho romano-ius commune-derecho europeo, Madrid, Edisofer, 2007, p. 248 ss.

${ }^{12}$ Vid. HERRERA BRAVO, R., El Derecho romano en la cultura jurídica del siglo XXI, Jaén, Universidad de Jaén, 2007 , p. 39 ss.

${ }^{13}$ HERRERA BRAVO, R., El Derecho romano en la cultura jurídica del siglo XXI, cit., p.43.

${ }^{14}$ FARGNOLI, I., «'Gentes europaeas [...] eo se iure regi passas esse'. A propósito de la armonización del derecho europeo», en RGDR, n 25, diciembre 2015, p. 22 ss.

${ }^{15}$ KOSCHAKER, P., Europa y el Derecho romano, (trad. esp.), Madrid, Ed. Revista de Derecho Privado, 1955, p. 317 ss. 
al cual se le abre cortésmente la puerta cuando llama, a quien se escucha con respeto y a quien se acompaña hasta la puerta para despedirle. En Alemania (extendámoslo a todos los ordenamientos jurídicos europeos continentales), en cambio, es arrojado con insultos ${ }^{16}$, simplemente porque en los años de juventud se permitió fumar sus pipas con excesiva familiaridad en los salones de doña Germania, y el humo de su tabaco ennegreció los muebles y la seda de las tapicerías con tal intensidad, que hasta la fecha, el procedimiento mejor, no ha podido suprimir el fuerte aroma que dejara".

\section{CONSECUENCIAS DEL BREXIT PARA EL DERECHO PRIVADO EU- ROPEO}

El 23 de junio de 2016, con gran sorpresa, los británicos decidieron abandonar la Unión. A fuer de ser sinceros, también es preciso reconocer que nunca se integraron al cien por cien, y en muchísimas ocasiones trataron de paralizarlo, o al menos ralentizarlo. Los especialistas invocan el art. 50 del Tratado de la Unión ${ }^{17}$, como base jurídica para formalizar la salida, pero, como no existen precedentes, todo es una novedad, de ahí que la incertidumbre aún sea mayor. Compartimos las palabras de MARTíN DELGADO, cuando afirma que "Salir no es más fácil que entrar. Decir adiós es muy sencillo; despedirse no lo es tanto"18. Lo que sí parece seguro, es que las negociaciones no son fáciles, previsiblemente no se rompan todos los vínculos, muchos se mantendrán mediante acuerdos bilaterales; se ignora el modelo de relación posterior a la salida, pero seguro que el "divorcio" no será excesivamente traumático, aunque haya sido originado por una decisión unilateral. Lo cierto, es que estamos ante una situación nueva, en absoluto fácil, sobre la que solamente el tiempo pondrá cordura. En la literatura vertida sobre el Brexit, impera, especialmente, la preocupación por la situación económica, los servicios financieros, las sociedades, la situación de los emigrantes, la movilidad de las personas, los trabajadores, etc. ${ }^{19}$.

${ }^{16}$ Así, el Punto 19 del Programa del Partido Nacional-Socialista Alemán.- "Exigimos que el Derecho romano, que responde a una concepción materialista del mundo, sea sustituido por un Derecho común alemán”. El 24 de febrero de 1920, a petición de HITLER, tuvo lugar en Munich un mitin multitudinario del Deutsche Arbeiter Partei (Partido Obrero Alemán); Hitler leyó el Programa de 25 puntos del NSDAP, (Nazionalsozialistische Deutsche Arbeiterpartei), que fueron la base y fundamento del programa político del nacionalsocialismo.

17 Artículo 50.- 1. Todo Estado miembro podrá decidir, de conformidad con sus normas constitucionales, retirarse de la Unión.

2. El Estado miembro que decida retirarse notificará su intención al Consejo Europeo. A la luz de las orientaciones del Consejo Europeo, la Unión negociará y celebrará con ese Estado un acuerdo que establecerá la forma de su retirada, teniendo en cuenta el marco de sus relaciones futuras con la Unión. Este acuerdo se negociará con arreglo al apartado 3 del artículo 218 del Tratado de Funcionamiento de la Unión Europea. El Consejo lo celebrará en nombre de la Unión por mayoría cualificada, previa aprobación del Parlamento Europeo.

3. Los Tratados dejarán de aplicarse al Estado de que se trate a partir de la fecha de entrada en vigor del acuerdo de retirada o, en su defecto, a los dos años de la notificación a que se refiere el apartado 2, salvo si el Consejo Europeo, de acuerdo con dicho Estado, decide por unanimidad prorrogar dicho plazo.

4. A efectos de los apartados 2 y 3 , el miembro del Consejo Europeo y del Consejo que represente al Estado miembro que se retire no participará ni en las deliberaciones ni en las decisiones del Consejo Europeo o del Consejo que le afecten.

La mayoría cualificada se definirá de conformidad con la letra b) del apartado 3 del artículo 238 del Tratado de Funcionamiento de la Unión Europea.

5. Si el Estado miembro que se ha retirado de la Unión solicita de nuevo la adhesión, su solicitud se someterá al procedimiento establecido en el artículo 49.

18 MARTÍN DELGADO, I., «"Brexit means Brexit”... o no. Especulaciones, conjeturas y algunas consideraciones jurídicas a propósito de la decisión del Reino Unido de retirarse de la Unión Europea en el contexto del artículo 50 TUE», en El Cronista del Estado Social y Democrático de Derecho, nº 64, noviembre 2016, p. 31.

${ }^{19}$ El no 64, noviembre 2016, de El Cronista del Estado Social y Democrático de Derecho está dedicado exclusivamente a abordar el tema del Brexit. Entre sus interesantes artículos de opinión no se aborda en profundidad la cuestión jurídica, ni cual vaya a ser el marco jurídico que nos encontremos tras la salida del RU, ni si se mantendrá el importante 
El enorme impacto que el Brexit va a tener en el ámbito del derecho privado, una vez que se produzca la desvinculación definitiva, no se va a poder solucionar con reglas comunes, pues ya no habrá lugar a ello, dentro de la estructura política de la UE. Cierto que las relaciones comerciales y especialmente las personales tendrán que continuar, pero no podrán ser bajo el mismo paraguas legal. Será preciso alcanzar acuerdos bilaterales en materia comercial, financiera, concursal, aduanera, libre movilidad de personas, mercado de seguros, fondos de pensiones, asistencia sanitaria, etc. "Mientras no haya convenios multilaterales o bilaterales del RU con la UE en su conjunto o separadamente con determinados países o grupos de países en materia de competencia judicial y ley aplicable, las respuestas dadas a los litigios internacionales que tengan relación con el RU no contarán con toda la seguridad y previsibilidad jurídica necesarias, por lo que conviene prestar una atención especial a la redacción de los contratos, especialmente incluyendo cláusulas de elección de foro y de ley aplicable claras para evitar problemas de interpretación, que no lleven a litigar - por tal descuido - a ciudadanos procedentes del sistema de Civil Law predominante en la UE, ante una jurisdicción con especiales características" ${ }^{20}$.

La oportunidad que representa para el Derecho romano el abandono de la UE por el RU, no va a tener las mismas consecuencias respecto de su idioma oficial. El inglés se ha convertido en la lengua universal para la comunicación en el mundo entero. Sin embargo, el Derecho romano está vinculado al latín, lengua extinta, en la que se nos brinda toda la información relacionada con el ordenamiento jurídico romano. El latín no se va a recuperar como lengua oficial, y aunque muchas lenguas de la Europa continental son de origen latino, las denominadas lenguas romances, otras no. Ello conlleva un problema complejo pero superable, porque muchas veces la terminología que se utilice estará en latín y, a decir verdad, nuestros alumnos llegan actualmente, a las aulas universitarias, sin haber estudiado ni tan siquiera un año de latín ${ }^{21}$, lo cual significa que todo lo que digamos en esa lengua, les resultará ininteligible. Esto no tiene que llevarnos a pretender una fácil divulgación del Derecho romano, traduciendo las palabras, algunas, por cierto, intraducibles, pues sería desdibujar la enseñanza del Derecho que realizamos. Si en otras asignaturas los alumnos van a aprender palabras en inglés, como leasing, factoring, renting, confirming, etc., sin preguntar por su versión castellana, entendemos que tampoco debemos hacerlo del latín, pues habrá expresiones perfectamente aceptadas, que aún hoy, e incluso por quienes no saben latín, son utilizadas con cierta frecuencia; pensemos, por ejemplo, en las expresiones: presunciones iuris tantum, o iuris et de iure, o in dubio pro reo o el principio non bis in idem, etc., frecuentemente usadas sin conocer la lengua latina $^{22}$.

proceso de unificación y de armonización llevado hasta la actualidad. No obstante, los artículos de recomendada lectura recogidos en la citada Revista son: LA TORRE, M., «El Brexit y la miseria del constitucionalismo global», p. 4 ss.; LÓPEZ ESCUDERO, M., «El incierto significado del Brexit», p. 12 ss.; SERRANO SANZ, J. Mª ., «La economía y el Brexit», p. 18 ss.; MARTÍN DELGADO, I., «"Brexit means Brexit”... o no. Especulaciones, conjeturas y algunas consideraciones jurídicas a propósito de la decisión del Reino Unido de retirarse de la Unión Europea en el contexto del artículo 50 TUE», p. 22 ss.; MENÉNDEZ, A. J., «De cómo convertir el Brexit en una oportunidad democrática», p. 32 ss.; SARMIENTO, D., «Y después del Brexit... ¿qué?», p. 42 ss.; SORIANO ARNANZ, A., «Brexit: alternativas e intereses en el proceso de negociación», p. 48 ss.; MUÑOZ MACHADO, S., «Perpetuidad: el principio ausente del programa de unificación europea», p. $56 \mathrm{ss}$.

20 RODRÍGUEZ, J. - LANNIER, S., Brexit y la Unión Europea: Consecuencias en el derecho internacional privado, en https://www.lleytons.com/wp-content/uploads/2018/04/lleytons-brexit-y-la-union-europea.pdf. (Última consulta realizada el 10 de mayo de 2019). Vid. también ARENAS GARCÍA, R., «Brexit y espacio europeo de libertad, seguridad y justicia: de lo deseable a lo posible», en DIÁLOGOS JURÍDICOS 2018, n 3, Anuario de la Facultad de Derecho de la Universidad de Oviedo, p.17 ss.

${ }^{21}$ Vid. RODRÍGUEZ ENNES, L., «La progresiva sustitución del latín universitario por las lenguas vernáculas», en GLOSSAE. European Journal of Legal History, nº 9, 2012, p. 97-109.

${ }^{22}$ Vid. BLANCH NOUGUÉS, J. M., Locuciones latinas y razonamiento jurídico. Una revisión a la luz del derecho romano y del derecho actual. Pro iure romano et lingua latina, Madrid, Dykinson, 2017. 
En definitiva, iteramos la opinión de PANERO ${ }^{23}$, cuando dice que "al hilo de esto, sirviéndonos de la distinción entre: posible, probable y seguro, a nuestro juicio, siendo «seguro», que si el significante lingua se asume con su valor de idioma, éste, como medio de comunicación ordinario, «comunitariamente» será el inglés, y más que «posible», que algún significante, que logró su plena lexicalización jurídica en Roma sea sustituido por el que se emplee en aquel idioma; sin embargo, es «probable» que, en este aspecto, por lo común, siga prevaleciendo su significante latino, y no admite duda, lo que equivale a contrario, a «es seguro», que el significante - latino o inglés - mantendrá el significado «romano». La Unión Europea tiene 24 lenguas oficiales, pero el inglés es el idioma extranjero más estudiado y dominado por los europeos, sin soslayar que entre los países que continúan en la UE, tanto Irlanda como Malta continúan teniendo el inglés como lengua oficial. Será difícil que el francés reemplace al inglés como lengua oficial de la Unión Europea, como se pide desde Francia.

\section{OTRA OPORTUNIDAD PARA EL DERECHO ROMANO}

Sin duda, estamos ante una de las mayores crisis políticas y económicas desde la Segunda Guerra mundial $^{24}$, que como ciudadanos debe preocuparnos y ocuparnos ${ }^{25}$. Como romanistas, debemos saber aprovechar la ocasión, para fortalecer nuestra disciplina, en el proceso de armonización o unificación jurídica de la Europa continental ${ }^{26}$. Tenemos ante nosotros la posibilidad de hacer del Brexit una oportunidad; es todo un desafío. Una ocasión para que, en la nueva redefinición jurídica unificadora, el Derecho romano recupere presencia, al menos como base común de todo el derecho unificador que se elabore. Ciertamente, la moderna ingeniería jurídica supera con creces lo establecido en el depurado ordenamiento jurídico romano, pero ello no debe ser obstáculo para que en las relaciones sustanciales entre los ciudadanos, que continuamos en la UE, en la que sigue primando un gran interés por la unificación legal, el Derecho romano sea capaz de aportar todo aquello básico y común que une, aun desconociéndolo, a los ordenamientos jurídicos de la Europa continental. Es decir, el punto de inflexión, en el que nos encontramos, también se dará en lo jurídico, y de la actual crisis surgirá un Derecho que romperá con lo anterior, y sus elementos distorsionantes. Como la retirada del RU de la UE, quiérase o no, también tendrá consecuencias en lo jurídico, será una buena ocasión para conseguir una Europa con fundamentos jurídicos más sólidos. Sobre todo, porque el Derecho romano, como columna vertebral de la tradición jurídica europea, "es un importante punto de partida para la historia del derecho europeo no solo debido a su herencia permanente, sino también porque este legado finalmente lo compartieron la mayoría de los europeos (si no todos)"27.

Hasta ahora nos encontrábamos con dos sistemas jurídicos bien diferenciados; uno abierto, el inglés, y otro cerrado o codificado, sistema que impera en todos los demás países de la Unión Europea. Con el Brexit desaparece de la UE la presencia de un sistema vivo, jurisprudencial, casuístico, el llamado case law method, caracterizado por su resistencia a la codificación.

${ }^{23}$ PANERO GUTIÉRREZ, R., «Valor actual del Derecho romano», en PANERO, R. et alii, El derecho romano en la Universidad del siglo XXI. Catorce siglos de historia y catorce de tradición, Valencia, Tirant lo Blanch, 2005 , p. 417.

${ }^{24}$ TUORI, K. - BJÖRKLUND, H., Roman Law and the Idea of Europe, Bloomsbury Academic, London, 2018.

${ }^{25}$ HERNÁNDEZ VILLALÓN, Y., El Brexit o el mayor reto jurídico de la Unión Europea, http://www.madrid.org/ revistajuridica/attachments/article/124/Brexit\%20o\%20el\%20mayor\%20reto\%20juridico\%20de\%201a\%20Union\%20Europea.pdf (Última consulta realizada el 10 de septiembre de 2019).

${ }^{26}$ Vid. El Notario del siglo XXI, Revista del Colegio Notarial de Madrid, septiembre-octubre, $\mathrm{n}^{\circ}$ 69, 2016, «El Brexit y armonización jurídica europea», (editorial) p. 3 ss.; TAPIA HERMIDA, A. J., «El Brexit y los mercados financieros», p. 6 ss. y HEREDIA, I. - THERY MARTÍ, A., «Brexit e insolvencia internacional», p. 10 ss., (http://www.elnotario.es/index.php/editorial/6978-el-brexit-y-armonizacion-juridica-europea) (Última consulta realizada el 10 de septiembre de 2019)

${ }^{27}$ HERZOG, T., Una breve historia del derecho europeo. Los últimos 2.500 años, cit., p. 17. 
Es un sistema en continua evolución, en el que los jueces y tribunales deciden sobre casos concretos, aplicando la técnica del precedente. Estas características le hacen muy diferente, y difícilmente compatible con los sistemas cerrados o codificados; de ahí las dificultades que ello conlleva, para poder armonizar el derecho europeo ${ }^{28}$. Por consiguiente, con su desconexión, el Brexit facilita cualquier intento de unificación del derecho europeo, por cuanto se trata de ordenamientos jurídicos con similar funcionamiento, y en los que la base común y originaria es el Derecho romano. Ello explica que lo veamos como una ventaja, para relanzar y revitalizar el trascendental papel que, en todo ello, ha de jugar el ordenamiento de Roma.

Entre los efectos colaterales del Brexit, al margen de otros, se encuentra el auge de la importancia del estudio e investigación del Derecho romano. Y ello, porque cada estado, cada país, tiene lo que denominamos su propio ordenamiento jurídico nacional. Cada país tiene su propio sistema jurídico y su peculiar manera de considerar el Derecho; tiene sus fuentes, sus modos de creación, interpretación y aplicación del derecho. Es decir, cada Estado tiene un derecho interno diferente al de los demás. Por lo tanto, los ordenamientos jurídicos, por principio, son nacionales y diferentes: tanto en los aspectos sustantivos como en los aspectos adjetivos o procesales. Pero existe un aspecto bien importante, y es que la inmensa mayoría de los ordenamientos jurídicos del mundo, salvo los que derivan del Common Law, de la tradición anglosajona, tienen, como se ha dicho, una base común que es el Derecho romano, auténtico precedente y base común de todos ellos.

En el ámbito de la UE, el Derecho está conformado por una constelación de ordenamientos autónomos, que necesitan de una aproximación ${ }^{29}$. Como todos los ordenamientos jurídicos son de base romanística, especialmente los de la Europa continental, el Derecho romano debe de tener un papel transcendental en su futura unificación ${ }^{30}$, sin que por ello se suprima la diversidad jurídica, propia de cada pueblo de los que conforman la UE. No obstante, es preciso que en el proceso de elaboración del nuevo derecho europeo, todos los países de cultura romanística reafirmen su formación jurídica; de ese modo, se evitará el riesgo de que la unificación del derecho europeo se realice en clave meramente administrativa o practicista ${ }^{31}$.

\section{FUNDAMENTOS ROMANÍSTICOS EN LOS FUTUROS PROYECTOS DE UNIFICACIÓN DEL DERECHO EUROPEO}

Tal ha sido la importancia del Derecho romano en la actual configuración europea, al menos desde el punto de vista jurídico, que, a medida que se avanza en la consolidación efectiva de la Unión, se observa la urgente necesidad de superar la dispersión legal de los distintos siste-

\footnotetext{
${ }^{28}$ Interesante trabajo el de CÁMARA LAPUENTE, S., «El hipotético “Código Civil Europeo”: ¿por qué, cómo y cuándo?», en Estudios jurídicos en homenaje al profesor Luis Díez-Picazo, (coord. por A. CABANILLAS), vol. 1, Madrid, Civitas, 2002 (Semblanzas. Derecho civil. Parte general), p. 347-380, en el que apunta que "las Directivas han sido la vía más efectiva para armonizar las tradiciones del Civil Law y el Common Law. La solución de unos principios cerrados en un Código final, aprobado por reglamento, sería, probablemente mal recibida en los países de Common Law". (http://www.unirioja.es/dptos/dd/civil/homPicazo.pdf) (Última consulta realizada el 10 de septiembre 2019).

29 Vid. PATTI, S., «Diritto europeo e codificazioni moderne», en Dai giuristi ai codici dai codici ai giuristi, (a cura di L. VACCA), Napoli, Jovene Editore, 2016, p. 87 ss.

30 Vid. MANNINO, V., «La tipicità dei diritti reali nella prospettiva di un diritto uniforme europeo», en Diritto romano, tradizione romanistica e formazione del diritto europeo. Giornate di studio in ricordo de G. PUGLIESE, (a cura di L. VACCA), Padova, CEDAM, 2008, p. 213-239.

${ }^{31}$ SOLIDORO MARUOTTI, L., La tradizione romanistica nel diritto europeo, II.- Dalla crisi dello ius commune alle codificacioni moderne, Torino, Giappichelli Editore, 2003, p. 227.
} 
mas normativos de los Estados que la conforman. Un ejemplo muy representativo es el Anteproyecto de Código Europeo de Contratos ${ }^{32}$, que se enmarca en la tendencia de unificación legal, perseguida a lo largo de todo el siglo veinte, y que esperemos se consolide en el veintiuno. Dicho proyecto, muy avanzado en su elaboración, tiene, como fin primordial, superar las diferencias y contrastes de los distintos ordenamientos europeos, al objeto de conseguir una eficacia real.

A lo largo de todo el proceso de elaboración del Código Europeo de Contratos se ha puesto de manifiesto la necesidad de huir de la artificiosidad, y buscar, por el contrario, unas bases comunes, que permitan aunar a los distintos sistemas. Por inverosímil que parezca, amén de mantener como estandarte el principio de la autonomía de la voluntad, propio de todos los ordenamientos europeos, destaca el origen e influencia del Derecho romano, y de su proyección histórica, en la inmensa mayoría de los sistemas de derecho privado que ahora se pretenden armonizar (unificar). La influencia se va a producir irremediablemente, porque el mencionado Código Europeo de Contratos se ha elaborado por una Comisión de juristas, sobre los que pesa, lo quieran o no, una importante formación romanística, e incluso alguno ha sido romanista de reconocido prestigio como WIEACKER ${ }^{33}$, STEIN, MAYER-MALY, STURM, MEDICUS, o VIGNERON ${ }^{34}$.

Por otro lado, se ha tomado como punto de referencia, y auxilio de las discusiones, el Código Civil italiano, concretamente su libro $4^{\circ}$, a propuesta de GIUSEPPE GANDOLFI, para proceder a plasmar, modificar, corregir o ampliar todo lo que sea necesario. Pues bien, resulta innegable que el Código Civil italiano es de base romanística, y por ello, el lenguaje, los términos y los conceptos van a ser comunes a la inmensa mayoría de los ordenamientos jurídicos europeos, pues el repertorio de conceptos básicos del derecho privado europeo, tradicionalmente, proceden del Derecho romano. Asimismo, la jurisprudencia romana nos enseñó que el jurista debe apegarse a la resolución del problema concreto, liberándose, en la medida de lo posible, de los excesos teóricos; por ello, es apreciable que el Código Europeo de Contratos busque soluciones prácticas, prescindiendo de los grandes enunciados dogmáticos.

En consecuencia, con la elaboración del Código Europeo de Contratos ${ }^{35}$ se está consolidando la vieja tendencia de no romper con la influencia de la historia, en el proceso de formación del derecho europeo. Nos encontramos, pues, ante una manifestación tardía de todo el proceso codificador, que comenzó allá en el siglo dieciocho, continuó en el diecinueve, en el veinte, llegando ahora, en el veintiuno, con carácter supranacional. Este proceso viene a confirmar aquel otro, que comenzó con la compilación del derecho privado romano en el Corpus Iuris Civilis, y

32 Vid. VATTIER FUENZALIDA, C., «El Derecho europeo de contratos y el anteproyecto de Pavía», en ADC., tomo LXI, fasc. IV, 2008, p. 1841 ss.

${ }^{33}$ Vid. JURISTAS UNIVERSALES, Juristas del s. XX, (R. DOMINGO, ed.) vol. IV, Madrid, Marcial Pons, 2004, s.v. FRANZ WIEACKER, p. 538 ss.

${ }^{34}$ HAMZA, G., Origine e sviluppo degli ordinamenti giusprivatistici moderni in base alla tradizione del Diritto romano, cit., p.16 ss.

35 Vid. texto en Código Europeo de Contratos. Academia de Iusprivatistas Europeos (Pavía), 2 tomos, (dir. C. VATTIER et alii), Madrid, Dykinson, 2003. "La idea del Proyecto de Pavía se debe al Prof. Gandolfi quien convocó en 1990, en dicha ciudad, un Congreso de civilistas europeos con la idea fundamental de responder a la pregunta de si la unidad de mercado, recogida reiteradamente en los Tratados del Mercado Común y de la UE, no implicaba necesariamente la unidad de las reglas contractuales aplicables a las transacciones intracomunitarias. La idea había empezado a discutirse previamente en círculos reducidos de juristas, con diversidad de respuestas; representaba un hito cualitativo del desarrollo del derecho comunitario en materia contractual; era novedosa y, hasta cierto punto, revolucionaria, pues de una parte significaba la culminación del proceso codificador europeo, desarrollado desde principios del siglo XIX, y, de otra, suponía en cierto modo, volver a los orígenes del Ius commune europeum, vivido efectivamente en el continente europeo varios siglos después de la Recepción”. Vid. GARCÍA CANTERO, G., La traducción española de la parte general del Código europeo de contratos, en www.unizar.es/derecho/nulidad/textos\%20legales/TRPAVIA.DOC (Última consulta realizada el 10 de septiembre de 2019). También del mismo Autor, «El Anteproyecto de Código Europeo de Contratos (Proyecto Gandolfi o del Grupo de Pavía)», en AA.VV., Derecho Privado Europeo (coord. S. CÁMARA LAPUENTE), Madrid, COLEX, 2003, p.205-216. 
su posterior estudio por los glosadores, comentaristas, humanistas, racionalistas, hasta llegar a la Pandectística, y a las codificaciones civiles europeas ${ }^{36}$.

Evidentemente, los codificadores no solamente se apoyan en los códigos de la Europa continental, principalmente en el italiano, sino que además han tenido en cuenta la vigente codificación del derecho de contratos representada en el Contract Code del Profesor MCGREGOR, pues el objetivo, no se olvide, era superar la dualidad del Civil Law y el Common Law, para obtener una unificación efectiva, que superara el pluralismo legal en materia de obligaciones y contratos, y que a la vez su aplicación no presentara especiales dificultades en ninguno de los países miembros de la Unión. Lo evidente es que con carácter previo a la actual situación, se había optado ya en favor de una solución de tipo codicístico. Pero el RU ya no es miembro de la UE. La necesidad de hacer guiños al derecho inglés llevó a que en el "Anteproyecto se hayan omitido las categorías abstractas, que podrían haber encontrado alguna resistencia en el derecho anglosajón; por eso, no se menciona el negocio jurídico, y la obligación aparece sólo como un efecto típico del contrato, aunque en la definición del mismo no ha podido dejar de aflorar la figura de la relación jurídica. Asimismo, si bien la buena fe impone, en el texto, estrictos deberes precontractuales, lo mismo que en materia de integración, efectos, incumplimiento y responsabilidad contractual, no aparece como criterio autónomo para interpretar el contrato, aun cuando el resultado de la interpretación no puede ser contrario a la misma, o al buen sentido" 37 .

A los romanistas, nos gustaría, aunque somos conscientes de que no se va a producir, que en el futuro Código Europeo de Contratos se hiciera alusión directa, y sin complejos, a todas las influencias recibidas del Derecho romano. Obviamente, nuestro derecho vigente tiene su antecedente en el Derecho romano, y ejemplos de ello pueden ponerse; un detalle muy descriptivo se observa en la legislación más reciente, si acudimos ad exemplum al derecho catalán ${ }^{38}$, pues en sus últimas leyes pueden leerse referencias explícitas al Derecho romano.

En otros dos proyectos de armonización del derecho común europeo, y nos referimos a los Principios de Derecho Contractual Europeo (PECL) ${ }^{39}$ y al Proyecto Marco Común de Referencia $(\mathrm{DCFR})^{40}$, también se observa que las diferentes comisiones tuvieron que rebajar sus pre-

${ }^{36}$ FERNÁNDEZ DE BUJÁN, F., «Retorno a Roma en la elaboración del futuro código europeo de contratos», en SDHI, $n^{\circ} 66,2000$, p. 245-261.

${ }^{37}$ Código Europeo de Contratos. Academia de Iusprivatistas Europeos (Pavía), tomo I, Madrid, Dykinson, 2003, (dir. C. VATTIER et alii), p. 19-20.

38 Ley 40/1991, de 30 diciembre, Código de sucesiones por causa de muerte en el Derecho Civil de Cataluña. (Vigente hasta el 1 de enero de 2009, derogado por la Ley 10/2008, de 10 de julio, del libro cuarto del Código Civil de Cataluña, relativo a las sucesiones). Ley 29/2002, de 30 de diciembre, primera Ley del Código civil de Cataluña. Ley 5/2006, de 10 de mayo, del libro quinto del Código Civil de Cataluña, relativo a los derechos reales.

${ }^{39}$ Los PECL es el resultado del trabajo llevado a cabo por un grupo de juristas europeos de diferentes Estados comunitarios desarrollados bajo el método comparativista. A comienzos de los ochenta, 1982, se constituyó un grupo bajo la dirección del profesor danés Ole Lando, conocido como la "Comisión Lando”. Esta comisión elaboró "Los Principios del derecho europeo de los contratos" cuya última versión apareció en 2002. Estos principios constituyen la obra más elaborada sobre la unificación del derecho de los contratos en Europa. La primera parte fue publicada en 1995, la segunda parte se terminó en 1996 aunque se publicó en 2000 y en 1997 comenzó la elaboración de la tercera parte. La relación que existe entre los PECL y los Principios UNIDROIT es absolutamente evidente. Muchas de las reglas incluso tienen una redacción idéntica cuando no muy similar y, además, muchos de los miembros de la Comisión Lando, incluido el propio Ole Lando, habían formado parte del grupo que redactó los Principios UNIDROIT. Vid. DÍEZ PICAZO, L. - ROCA TRIAS, E. - MORALES, A. M., Los Principios del Derecho Europeo de Contratos, Madrid, Civitas, 2002, p. 84.

40 “El Proyecto de Marco Común de Referencia comenzó a gestarse ya en el año 1989, cuando el Parlamento Europeo planteó la creación de un Código civil europeo. En el año 2009 se publicó una segunda versión del texto (la primera data de 2007). En buena medida el DCFR está basado en los Principios de derecho europeo de contratos (European Civil Code, 2009), principios elaborados en la década de los años ochenta por un grupo de expertos bajo la coordina- 
tensiones, ante las dificultades de conciliación del Civil Law y del Commom Law. Merece destacarse, que al menos los PECL tienen el mérito de haber hecho evidente la existencia de una base común entre los diferentes ordenamientos jurídicos europeos, así como la posibilidad de reunir principios de sistemas tan diferentes ${ }^{41}$. Y lo mismo puede decirse del DCFR, que también tuvo como condicionamiento inicial el obstáculo de las diferencias entre sistemas jurídicos. Ello dificultaba una total integración del derecho privado europeo, que ha obligado a dejar al margen de la armonización sectores tales como la familia, sucesiones, propiedad inmobiliaria, etc., centrándose exclusivamente en las obligaciones y contratos. Todo ello ha originado severas críticas, por haber propuesto un derecho privado europeo muy desequilibrado entre sus diferentes partes $^{42}$.

En fin, lo que se pretende es recordar que el ordenamiento jurídico romano es el inspirador de muchos de los principios del derecho europeo; no obstante, su recepción viene matizada por el devenir histórico, de tal modo que una cosa es que los grandes principios ondeen sobre la legislación y otra bien distinta que la regulación del particularizado casuismo sea idéntica. El Derecho romano debido a su implantación en prácticamente todos los planes de estudios jurídicos del mundo, eso sí, con intensidad y objetivos distintos, se ha convertido en una ciencia supranacional cuya importancia crece en proporción directa a las divergencias que existan entre los sistemas jurídicos, en este caso, europeos. Se trata del elemento histórico necesario para la interpretación de los ordenamientos europeos continentales.

No olvidamos, obviamente, que el Derecho romano ha influido más en unas zonas que en otras del derecho privado; esa influencia es más acusada en materia de obligaciones y contratos, o sucesiones que en materia de familia, por ejemplo; de ahí su importancia, en relación con el Código Europeo de Contratos ${ }^{43}$. En consecuencia, y aunque parezca que hacemos apología de la ciencia jurídica romana, conviene recordar que el saber humano no es más que la historia de la actividad del espíritu, y su transmisión solamente se obtiene a través de un exacto inventario de

ción del jurista danés Ole Lando. La revisión presentada en el año 2011, llamada Feasibility Study (estudio de viabilidad) (European Contract Law), representa el fundamento del trabajo para la elaboración de un futuro Derecho contractual europeo. El DCFR contiene una serie de principios, definiciones y reglas modelo de Derecho privado europeo que pretenden servir como preludio de un Marco Común de Referencia con respaldo político, dejando de ser un trabajo puramente académico". Vid. GROTHE, H., «The Common Frame of Reference for European Private Law», en http:// repository.usergioarboleda.edu.co/handle/11232/500. (Última consulta realizada el 10 de septiembre de 2019), "Actualmente, se desarrolla en Europa un fenómeno de integración normativa común de los intercambios de bienes y servicios, a partir de la "unificación" del Derecho de Contratos. Se ha establecido un conjunto normativo, denominado "Marco Común de Referencia", que funciona como normas modelo, definiciones básicas y principios fundamentales, sobre la base del "acervo comunitario" y las soluciones empíricas". Vid. OROZCO PARDO, G., Y MORENO NAVARRETE, M. A., «El contrato en el contexto de la unificación del derecho privado», en https://digitum.um.es/jspui/ bitstream/10201/28073/1/contratoenelcontexto.pdf. (Última consulta realizada el 10 de septiembre de 2019).

${ }^{41}$ LUCHETTI, G. - PETRUCCI, A., Fondamenti di diritto contrattuale europeo. Dalle radici romane al progetto dei Principles of European Contract Law della Commissione Lando, Bologna, Pàtron editore, 2006, p. 16.

42 Vid. LUCHETTI, G. - PETRUCCI, A., Fondamenti di diritto contrattuale europeo. Dalle radici romane al Draft Common Frame of Reference II. Materiali e commento, Bologna, Pàtron editore, 2010, Introduzione, p. 11 ss., y especialmente p. 27 ss. Igual, en Fondamenti romanistici del diritto europeo. Le obbligazioni e i contratti dalle radici romane al Draft Common Frame of Reference I, Bologna, Pàtron editore, 2010, Introduzione, p. 9 ss., y especialmente p. 25 ss.

${ }^{43} \mathrm{Si}$ el prestigioso historiador italiano P. GROSSI, La propiedad y las propiedades. Un análisis histórico, (traducción y "Prólogo para civilistas" de A. M. LÓPEZ Y LÓPEZ), Madrid, Civitas, 1992, p. 123 ss., veía de forma imaginaria al Code civil napoleónico como un palimpsesto jurídico, lo mismo podríamos decir del Código Europeo de Contratos por cuanto si por palimpsesto entendemos un "manuscrito antiguo que conserva huellas de una escritura anterior borrada artificialmente" (definición diccionario RAE), podría decirse que en este Proyecto, en algunos de sus apartados, si analizamos las disposiciones jurídicas que subyacen y que artificialmente se han querido borrar, encontramos el Derecho romano en su máximo esplendor. 
conceptos esenciales ${ }^{44}$. Las categorías jurídicas son como las categorías lógicas, que sólo cambiarán cuando cambie la naturaleza del hombre ${ }^{45}$.

Lo cierto, es que a pesar de los proyectos de unificación, a los que hemos hecho referencia, a día de hoy, se sigue necesitando un código para armonizar las relaciones comerciales, de un mercado libre y unitario, dentro de la Unión. Entre otras cosas, porque se necesitan reglas similares para crear un verdadero espacio económico. Similares, no significa que necesariamente tengan que ser idénticas, porque el objetivo no es tanto la igualdad formal, como la igualdad sustantiva de los actores económicos. Para ello, es necesario un código europeo de los negocios, que supla la ausencia de unificación. Unificación en muchas materias, como por ejemplo, derecho de sociedades, derecho bursátil, derecho concursal, derecho bancario, derecho de los seguros, derecho de los mercados financieros, derecho de la propiedad intelectual, derecho del comercio electrónico, derecho laboral, derecho fiscal, etc. ¿Y de qué medios disponemos para elaborar este código? Pues, en opinión de BAYEELON Y BERNARD, sería muy adecuado apoyarse en la tradición continental, basándose en la codificación europea, sobre todo de países de tradición romano-germánica, como Francia, Alemania, Italia y Bélgica, porque Europa es la mejor representante del derecho romano-germánico ${ }^{46}$.

\section{CONCLUSIÓN}

Europa necesita, con cierta urgencia, unificar sus ordenamientos, tener leyes uniformes, buscar la regla "igual" para sus ciudadanos, y ello se vería favorecido, si en todos los planes de estudio, de todas las Facultades de Derecho de todos los países que conforman la UE, se estudiaran asignaturas comunes de formación general, entre las que, sin duda, el Derecho romano debiera tener un papel destacado. Esta formación romanista permitiría una más fácil interpretación, y comprensión unitaria, del derecho positivo, por parte de todos los juristas europeos. Obviamente, hablamos de una apuesta de largo recorrido, que no se soluciona en un breve espacio de tiempo. Pero sería muy oportuno, que nuestras autoridades se convencieran de ello, y comenzaran a ponerlo en práctica. Necesitamos una ciencia jurídica europea, que esté de acuerdo en lo esencial, y sea quien inspire, con su actividad legislativa, los nuevos textos de derecho positivo. Se trata de lograr un orden jurídico común. Y nada mejor que el Derecho romano, que es la casa común del jurista europeo.

Nos hallamos en un buen momento para plantearnos cuál deba ser la responsabilidad del romanista en orden a la enseñanza del Derecho romano, porque paulatinamente hemos perdido peso específico en la formación de los juristas europeos. ¿A quién debe imputarse la reducción de la presencia del Derecho romano en los actuales Planes de estudio? ¿A los romanistas o a la situación coyuntural en que nos movemos? Se trata de una discusión evidentemente teórica. Quizás, una so-

44 Vid. CASAVOLA, F. P., «L'educazione del giurista tra memoria e ragione», INDEX. Quaderni camerti di studi romanistici, 19, 1991, p. 325.

45 «Sull'Europa, sull'insegnamento e l'applicazione del Diritto romano (1922-1974): citazioni scelte di Giorgio La Pira», a cura di P. A. CATALANO, INDEX. Quaderni camerti di studi romanistici, 23, 1995, p. 32.

${ }^{46}$ Vid. el interesante artículo sobre esta cuestión de BAYEELON, P. - BERNARD, E., «Pour un Code européen des affaires», en Question d'Europe n ${ }^{\circ}$ 418, p. 1-9: (http://www.robert-schuman.eu/fr/questions-d-europe/0418-pourun-code-europeen-des-affaires) (Última consulta realizada el 10 de septiembre de 2019). 
lución, como apunta TORRENT, fuera enseñar una asignatura de "Fundamentos del derecho europeo" ${ }^{\prime 7}$ como se hace en Italia ${ }^{48}$, no obstante, para explicar ese contenido, es preciso que previamente se conozca el ordenamiento jurídico romano. Por consiguiente, como dice FIORAVANTI, refiriéndose a los historiadores del Derecho, los romanistas también lo somos, "debemos formular propuestas históricas y culturales adecuadas al presente, si queremos elaborar una estrategia de combate adecuada, con vistas a mantener y promover un papel relevante para las disciplinas histórico-jurídicas en las Facultades de Derecho"49. En definitiva, dice LUCHETTI, la idea del derecho común europeo es, "una huella que los romanistas deben perseguir, en la consciencia de que la transnacionalidad de nuestra disciplina puede ayudar a hacer resurgir la idea, según la cual la exigencia de un ius commune Europaeum no es una quimera del mundo contemporáneo, sino que es una realidad histórica fuerte y evidente, transmitida por nuestra parte, en primer lugar, a las futuras generaciones" ${ }^{\prime 50}$.

Todo lo anterior viene favorecido por el Brexit. Las consecuencias serán muchas, fundamentalmente económicas, aunque todo dependerá del proceso de negociación de la salida, lo cual ha de suponer un paso adelante de la Unión Europea hacia su renovación. Dicho proceso de negociación tendrá previsiblemente un impacto muy significativo, sobre la fortaleza de la integración europea en el futuro. Cierto que como ciudadanos europeos tienen que preocuparnos las consecuencias de todo tipo, que deriven del abandono unilateral británico, pero como juristas debe preocuparnos, especialmente, nuestra parcela jurídica, que finalmente influye en el todo. La regulación jurídica cambia los destinos de la sociedad. Para conseguirlo, y descendiendo un peldaño más, como romanistas, no por ello dejamos de ser juristas, tenemos que colaborar y reivindicar la trascendencia de nuestra ciencia, en el futuro cuerpo legal positivo que se desarrolle en la UE.

El 22 de octubre de 1957 el periódico de 'The Times of London', publicaba el siguiente titular: "Fuerte niebla en el Canal. El Continente, aislado". Este legendario titular representaba perfectamente la visión que desde el RU se tenía de Europa. Pero curiosamente, más de sesenta

${ }^{47}$ Entiende TORRENT, A., en su interesantísima y bien documentada obra Fundamentos del derecho europeo. Ciencia del derecho: derecho romano-ius commune-derecho europeo, cit., que es imprescindible introducir en los planes de estudio una nueva asignatura: "Fundamentos del derecho europeo", para entender el nuevo ius commune europaeum aún in fieri. Vid. también del mismo Autor, «Fundamentos del derecho europeo (Derecho romano - Ciencia del Derecho - Derecho europeo)», en AFDUDC, n 11, 2007, p. 941 - 995.

${ }^{48}$ La Facoltà di Giurisprudenza de la Università degli Studi di Milano-Bicocca la denomina Fondamenti romanistici del diritto privato europeo, (https://www.unimib.it/ugov/degreecourse/154583) (Última consulta realizada el 10 de septiembre de 2019). También tiene otras denominaciones, como por ejemplo: Fondamenti romanistici del diritto europeo e Storia delle codificazioni moderne, Università di Siena (https://www.dgiur.unisi.it/it/didattica/insegnamenticorso-di-laurea-magistrale-ciclo-unico-giurisprudenza/fondamenti-romanistici) (Última consulta realizada el 10 de septiembre de 2019); Fondamenti romanistici del diritto europeo, Università di Bologna (https://www.unibo.it/it/didattica/insegnamenti/insegnamento/2018/204290) (Última consulta realizada el 10 de septiembre de 2019); Fondamenti romanistici del diritto europeo en Università degli Studi di Trieste (https://iuslit.units.it/it/didattica/lezioni-fondamenti-romanistici-del-diritto-europeo-1-053gi-1-20132014/3561) (Última consulta realizada el 10 de septiembre de 2019); Fondamenti romanistici del diritto europeo en Università degli Studi di Perugia (https://www.unipg.it/didattica/offerta-formativa/offerta-formativa-2018-19?idins=132201), (Última consulta realizada el 10 de septiembre de 2019); Fondamenti romanistici del diritto europeo en Università degli Studi di Bergamo (https://www.unibg.it/ugov/ degreecourse/44834), (Última consulta realizada el 10 de septiembre de 2019); Fondamenti romanistici del diritto europeo en Università degli Studi di Padova (https://didattica.unipd.it/off/2018/LT/EP/SP1841/000ZZ/EPP8084885/ N0), (Última consulta realizada el 10 de septiembre de 2019); etc. Más información en BUENO DELGADO, J. A., «Dal Diritto romano ad un diritto europeo comune: L'importanza e l'influenza del diritto romano oggi, con particolare riferimento all'Unione europea», en RGDR 26, 2016, p.14.

${ }^{49}$ FIORAVANTI, M., «El papel de las disciplinas histórico-jurídicas en la formación del jurista europeo», en CIAN 9 , 2006, p. 347 y en «Lo que está en juego. El papel de las disciplinas histórico-jurídicas en la formación del jurista europeo», en SCDR, XIX, 2006, p. 19.

${ }^{50}$ LUCHETTI, G., Las interferencias en el cumplimiento de la condición, entre tradición romanística y globalización jurídica. Conferencia impartida el jueves 11 de abril de 2019, en el XXI Congreso Internacional y XXIV Congreso Iberoamericano de Derecho Romano, celebrado en la Universidad de Oviedo, y cuyo tema de debate fue: "Fundamentos romanísticos del derecho de la Unión Europea y de los países iberoamericanos". 
años después, las cosas han cambiado; quien ahora queda aislado del Continente europeo, cierto que por voluntad propia, es el RU, y dado que las ocasiones, para el fortalecimiento de una ciencia, como la nuestra, son escasas, aprovechemos la ocasión que se nos brinda. Es el momento oportuno para comenzar, y sin duda lograr a partir de ahora, una ciencia jurídica europea continental común de base romanista, pues la presencia del Commom Law siempre dificultó la posible unificación de los ordenamientos jurídicos continentales. Hasta ahora, el problema residía en compaginar dos sistemas jurídicos bien diferenciados, el inglés, Commom Law, abierto, y el continental, Civil Law, cerrado o codificado. La "nueva" UE puede reorganizarse, bajo un mismo sistema jurídico que armonice diferentes ordenamientos jurídicos, con un denominador común: el Derecho romano.

Si así se produjere, sería oportuno recordar las palabras de Goethe, para quien el Derecho romano es algo perenne que como un pato se sumerge, desaparece durante un tiempo, pero nunca se pierde del todo y siempre reaparece vivo ("gleich einer untertanchenden Ente sich zwar von Zeit zu Zeit verbirgt, aber nie ganz verloren geht und immer wieder ainmal lebending hervortritt" $)^{51}$. Ciertamente, la actual situación jurídica de la UE nada tiene que ver con la Alemania de Goethe, pero la imagen del ánade zambulléndose y emergiendo, no sin esfuerzo, ha sido una constante histórica desde el principio de los tiempos, y es una metáfora que sigue siendo válida para la realidad actual del Derecho romano, ordenamiento que nunca desaparece definitivamente, por más que algunos lo intenten.

\section{REFERENCIAS}

ACQUARONE, L. et alii, Sistemi giuridici nel mondo, 2. ed., Torino, Giappichelli Editore, 2016.

AJANI, G. et alii, Sistemas jurídicos comparados. Lecciones y materiales, (trad. español), Barcelona, Publicacions i Edicions, Universitat de Barcelona, 2010.

ARENAS GARCÍA, R., «Brexit y espacio europeo de libertad, seguridad y justicia: de lo deseable a lo posible», en DIÁLOGOS JURÍDICOS 2018, n. 3, Anuario de la Facultad de Derecho de la Universidad de Oviedo, p.17 ss.

BAYEELON, P. - BERNARD, E., «Pour un Code européen des affaires», en Question d'Europe $\mathrm{n}^{\circ}$ 418, p. 1-9: (http://www.robert-schuman.eu/fr/questions-d-europe/0418-pour-un-codeeuropeen-des-affaires) (Última consulta realizada el 10 de septiembre de 2019).

BLANCH NOUGUÉS, J. M., Locuciones latinas y razonamiento jurídico. Una revisión a la luz del derecho romano y del derecho actual. Pro iure romano et lingua latina, Madrid, Dykinson, 2017.

BUENO DELGADO, J. A., «Dal Diritto romano ad un diritto europeo comune: L'importanza e l'influenza del diritto romano oggi, con particolare riferimento all'Unione europea», en RGDR 26, 2016.

CÁMARA LAPUENTE, S., «El hipotético “Código Civil Europeo”: ¿por qué, cómo y cuándo?», en Estudios jurídicos en homenaje al profesor Luis Díez-Picazo, (coord. por A. CABANILLAS), vol. 1, Madrid, Civitas, 2002 (Semblanzas. Derecho civil. Parte general), p. 347-380.

${ }^{51}$ ECKERMANN, J.P., Gespräche mit Goethe in den letzten Jahren seines Lebens, 3, I, Th. Knaur Nachf., Berlin, 1924, p. 74 (Eckermann sitúa la conversación con Goethe, el lunes 6 de abril de 1829). 
CASAVOLA, F. P., «L'educazione del giurista tra memoria e ragione», INDEX. Quaderni camerti di studi romanistici 19, 1991.

CATALANO, P.A., «Sull’Europa, sull'insegnamento e l'applicazione del Diritto romano (19221974): citazioni scelte di Giorgio La Pira», en INDEX. Quaderni camerti di studi romanistici 23, 1995.

Código Europeo de Contratos. Academia de Iusprivatistas Europeos (Pavía), 2 tomos, (dir. C. VATTIER et alii), Madrid, Dykinson, 2003.

DÍEZ PICAZO, L. - ROCA TRIAS, E. - MORALES, A. M., Los Principios del Derecho Europeo de Contratos, Madrid, Civitas, 2002.

ECKERMANN, J.P., Gespräche mit Goethe in den letzten Jahren seines Lebens, 3, I, Th. Knaur Nachf., Berlin, 1924.

FARGNOLI, I., «'Gentes europaeas ... eo se iure regi passas esse’. A propósito de la armonización del derecho europeo», en RGDR, n. 25, diciembre 2015.

FERNÁNDEZ DE BUJÁN, F., «Retorno a Roma en la elaboración del futuro código europeo de contratos», en SDHI, n. 66, 2000.

FERNÁNDEZ DE BUJÁN, A., «Ciencia jurídica europea y derecho comunitario: Ius romanum. Ius commune. Cammon Law». Civil Law, en RGDR, n. 10, 2008.

FERNÁNDEZ DE BUJÁN, A., «Ciencia jurídica europea y derecho comunitario: Ius romanum. Ius commune. Cammon Law. Civil Law», en GLOSSAE. European Journal of Legal History, n. 13, 2016.

FIORAVANTI, M., «El papel de las disciplinas histórico-jurídicas en la formación del jurista europeo», en CIAN 9, 2006.

FIORAVANTI, M., «Lo que está en juego. El papel de las disciplinas histórico-jurídicas en la formación del jurista europeo», en SCDR, XIX, 2006.

GAMBARO, A. - SACCO, R., Sistemi giuridici comparati, 4 . ed., Utet Giuridica, Milano, 2018.

GARCÍA CANTERO, G., La traducción española de la parte general del Código europeo de contratos, en www.unizar.es/derecho/nulidad/textos legales/TR-PAVIA.DOC (Última consulta realizada el 10 de septiembre de 2019).

GARCÍA CANTERO, G., «El Anteproyecto de Código Europeo de Contratos (Proyecto Gandolfi o del Grupo de Pavía)», en AA.VV., Derecho Privado Europeo (coord. S. CÁMARA LAPUENTE), Madrid, COLEX, 2003.

GROSSI, P., La propiedad y las propiedades. Un análisis histórico, (traducción y "Prólogo para civilistas" de A. M. López y López), Madrid, Civitas, 1992.

GROTHE, H., The Common Frame of Reference for European Private Law, en http://repository.usergioarboleda.edu.co/handle/11232/500. (Última consulta realizada el 10 de septiembre de 2019).

HAMZA, G., Origine e sviluppo degli ordinamenti giusprivatistici moderni in base alla tradizione del Diritto romano, Santiago de Compostela, Andavira, 2013.

HEREDIA, I. - THERY MARTÍ, A., «Brexit e insolvencia internacional», en El Notario del siglo XXI, Revista del Colegio Notarial de Madrid, septiembre-octubre, n. 69, 2016, p. 10 ss., 
(http://www.elnotario.es/index.php/editorial/6978-el-brexit-y-armonizacion-juridica-europea) (Última consulta realizada el 10 de septiembre de 2019).

HERNÁNDEZ VILLALÓN, Y., «El Brexit o el mayor reto jurídico de la Unión Europea», http://www.madrid.org/revistajuridica/attachments/article/124/Brexit o el mayor reto juridico de la Union Europea.pdf (Última consulta realizada el 10 de septiembre de 2019).

HERRERA BRAVO, R., EI Derecho romano en la cultura jurídica del siglo XXI, Jaén, Universidad de Jaén, 2007.

HERRERA BRAVO, R. - SALAZAR REVUELTA, M.. - SALAZAR REVUELTA, A., «Ius Commune versus Derecho común europeo», en RGDR, n.. 10, 2008.

HERZOG, T., Una breve historia del derecho europeo. Los últimos 2.500 años, Madrid, Alianza Editorial S.A., (trad. esp. COLL RODRÍGUEZ, M.A.), 2019.

HEUSER B., Brexit in History: Sovereignty or a European Union?, London, Reino Unido, ed. C. Hurst \& Co. Ltd., 2019.

JURISTAS UNIVERSALES, Juristas del s. XX, (R. DOMINGO, ed.) vol. IV, Madrid, Marcial Pons, 2004, s.v. FRANZ WIEACKER, p. 538 ss.

KOSCHAKER, P., Europa y el Derecho romano, (trad. esp.), Madrid, Ed. Revista de Derecho Privado, 1955.

LA TORRE, M., «El Brexit y la miseria del constitucionalismo global», en El Cronista del Estado Social y Democrático de Derecho, n. 64, noviembre 2016, p. 4 ss.

LÓPEZ ESCUDERO, M., «El incierto significado del Brexit», en El Cronista del Estado Social y Democrático de Derecho, n. 64, noviembre 2016, p. 12 ss.

LUCHETTI, G. - PETRUCCI, A., Fondamenti di diritto contrattuale europeo. Dalle radici romane al progetto dei Principles of European Contract Law della Commissione Lando, Bologna, Pàtron editore, 2006.

LUCHETTI, G. - PETRUCCI, A., Fondamenti romanistici del diritto europeo. Le obbligazioni e i contratti dalle radici romane al Draft Common Frame of Reference I, Bologna, Pàtron editore, 2010.

LUCHETTI, G. - PETRUCCI, A., Fondamenti di diritto contrattuale europeo. Dalle radici romane al Draft Common Frame of Reference II. Materiali e commento, Bologna, Pàtron editore, 2010.

MANNINO, V., «La tipicità dei diritti reali nella prospettiva di un diritto uniforme europeo», en Diritto romano, tradizione romanistica e formazione del diritto europeo. Giornate di studio in ricordo de G. PUGLIESE, (a cura di L. VACCA), Padova, CEDAM, 2008.

MARTÍN DELGADO, I., «“Brexit means Brexit”... o no. Especulaciones, conjeturas y algunas consideraciones jurídicas a propósito de la decisión del Reino Unido de retirarse de la Unión Europea en el contexto del artículo 50 TUE», en EI Cronista del Estado Social y Democrático de Derecho, n. 64, noviembre 2016, p. 22 ss.

MENÉNDEZ, A. J., «De cómo convertir el Brexit en una oportunidad democrática», en El Cronista del Estado Social y Democrático de Derecho, n. 64, noviembre 2016, p. 32 ss.

MUÑOZ MACHADO, S., «Perpetuidad: el principio ausente del programa de unificación europea», en El Cronista del Estado Social y Democrático de Derecho, n. 64, noviembre 2016, p. $56 \mathrm{ss}$. 
MURILlO VILLAR, A., ¿Para qué sirve el Derecho romano? Razones que justifican su docencia e investigación en el siglo XXI, Santiago de Compostela, Andavira, 2018.

OROZCO PARDO, G., Y MORENO NAVARRETE, M. A., «El contrato en el contexto de la unificación del derecho privado», en https://digitum.um.es/jspui/bitstream/10201/28073/1/ contratoenelcontexto.pdf (Última consulta realizada el 10 de septiembre de 2019).

PANERO GUTIÉRREZ, R., «Valor actual del Derecho romano», en PANERO, R. et alii, El derecho romano en la Universidad del siglo XXI. Catorce siglos de historia y catorce de tradición, Valencia, Tirant lo Blanch, 2005.

PATTI, S., «Diritto europeo e codificazioni moderne», en Dai giuristi ai codici dai codici ai giuristi, (a cura di L. VACCA), Napoli, Jovene Editore, 2016.

ROBLES VELASCO, L. M., «El futuro código europeo de contratos, ¿una nueva recepción?», en RIDROM, n. 5, octubre 2010.

RODRÍGUEZ, J. - LANNIER, S., «Brexit y la Unión Europea: Consecuencias en el derecho internacional privado», en https://www.lleytons.com/wp-content/uploads/2018/04/lleytons-brexit-y-la-union-europea.pdf.

RODRÍGUEZ ENNES, L., «La progresiva sustitución del latín universitario por las lenguas vernáculas», en GLOSSAE. European Journal of Legal History, n. 9, 2012.

SARMIENTO, D., «Y después del Brexit... ¿qué?», en El Cronista del Estado Social y Democrático de Derecho, n. 64, noviembre 2016, p. 42 ss.

SERRANO SANZ, J. M.., «La economía y el Brexit», en El Cronista del Estado Social y Democrático de Derecho, n. 64, noviembre 2016,p. 18 ss.

SOLIDORO MARUOTTI, L., La tradizione romanistica nel diritto europeo, II Dalla crisi dello ius commune alle codificacioni moderne, Torino, Giappichelli Editore, 2003.

SORIANO ARNANZ, A., «Brexit: alternativas e intereses en el proceso de negociación», en El Cronista del Estado Social y Democrático de Derecho, n. 64, noviembre 2016, p. 48 ss.

STÜRNER, M., «Tendiendo un puente entre el Common Law y el derecho continental. ¿Constituyen las diferentes metodologías de trabajo un obstáculo contra una mayor armonización del derecho privado europeo?», en Revista jurídica Universidad Autónoma de Madrid, n. 15, 2007.

TAPIA HERMIDA, A. J., «El Brexit y los mercados financieros», en El Notario del siglo XXI, Revista del Colegio Notarial de Madrid, septiembre-octubre, n. 69, 2016, p. 6 ss. (http://www.elnotario.es/index.php/editorial/6978-el-brexit-y-armonizacion-juridica-europea)

(Última consulta realizada el 10 de septiembre de 2019).

TORRENT, A., Fundamentos del derecho europeo. Ciencia del derecho: Derecho romano-ius commune-derecho europeo, Madrid, Edisofer, 2007.

TORRENT, A., «Fundamentos del derecho europeo (Derecho romano - Ciencia del Derecho Derecho europeo)», en AFDUDC, n. 11, 2007.

TUORI, K. - BJÖRKLUND, H., Roman Law and the Idea of Europe, Bloomsbury Academic, London, 2018.

VAN CAENEGEM, R.C., Pasado y futuro del derecho europeo, dos milenios de unidad y diversidad, Santiago de Chile, Chile, ed. Olejnik, 2019. 
El Brexit: todo un reto para el Derecho Romano

VATTIER FUENZALIDA, C., «El Derecho europeo de contratos y el anteproyecto de Pavía», en ADC., tomo LXI, fasc. IV, 2008.

Recebido em: 17 set. 2019.

Aceito em: 12 nov. 2019. 